\title{
Prevalence of bovine genital campylobacteriosis and trichomonosis of bulls in northern Nigeria
}

\author{
Hassan M Mai ${ }^{1}{ }^{2}$, Peter C Irons ${ }^{1}$, Junaidu Kabir ${ }^{3}$ and Peter N Thompson ${ }^{1}$
}

\begin{abstract}
Background: A survey was conducted to determine the prevalence of campylobacteriosis and trichomonosis, and their concurrence with brucellosis, in cattle in three states of northern Nigeria.

Methods: A total of 602 preputial samples was collected from bulls in 250 herds and tested using culture and identification. Various indigenous and exotic breeds were studied and four major management systems were encountered. Age of the cattle was estimated using dentition, farm records or cornual rings.

Results: The estimated true animal-level prevalence of Campylobacter fetus infection was 16.4\% (95\% Cl: 13.0-20.7), of which $18.5 \%$ was C. f. fetus and $81.5 \%$ was C.f. venerealis. Of the latter, $92 \%$ were C. f. venerealis biovar intermedius strains. Animal-level prevalences in Adamawa, Kano and Kaduna states were 31.8\%, 11.6\% and 8.3\% respectively, and were highest in bulls $>7$ years old (33.4\%) and in the Gudali breed (28.8\%). Of the 250 herds, 78 (25.5\%, 95\% Cl: 19.4-32.7) had at least one infected bull, and herd prevalence was highest in the pastoral management system (43.5\%). After adjustment for confounding using multivariable analysis, the odds of $C$. fetus infection were highest in Adamawa state $(P<0.01)$, in the pastoral management system $(P<0.01)$, and in bulls $>7$ years old $(P=0.01)$, and tended to be higher in Bos taurus breeds $(P=0.06)$. There was a strong positive association between the presence of campylobacteriosis and brucellosis $(P<0.01)$, both within bulls $(\mathrm{OR}=8.3)$ and within herds $(\mathrm{OR}=16.0)$. Trichomonosis was not detected in any herds.
\end{abstract}

Conclusion: Bovine genital campylobacteriosis is prevalent particularly in the pastoral management system in northern Nigeria, with C. f. venerealis biovar intermedius as the major aetiology. There was a strong positive correlation between the occurrence of campylobacteriosis and brucellosis. No evidence of trichomonosis was found in herds in this study.

Keywords: Bovine, Brucellosis, Campylobacteriosis, Nigeria, Preputial samples, Trichomonosis

\section{Background}

Bovine genital campylobacteriosis (BGC) and trichomonosis are economically important venereal diseases that occur worldwide and are characterized by infertility, embryo mortality, abortion, irregular oestrous cycles and long calving intervals [1-4]. The diseases tend to occur in areas with extensive cattle management and natural breeding [5-7]. Pregnancy rate in BGC can be as low as $20 \%$ and abortion rate as high as $10 \%$ [8]. Sterility may occur in up to $11 \%$ of

\footnotetext{
* Correspondence: hassanmai65@gmail.com

'Department of Production Animal Studies, Faculty of Veterinary Science, University of Pretoria, Private Bag X04, Onderstepoort 0110, South Africa

${ }^{2}$ Animal Production Programme, School of Agriculture and Agricultural Technology, Abubakar Tafawa Balewa University, P. M. B. 0248, Bauchi 740001, Nigeria

Full list of author information is available at the end of the article
}

infected heifers [5]. Trichomonosis is also associated with mild to severe pyometra, low birth weight and decreased calf crop of up to $50 \%[6,9]$.

The most common cause of BGC is Campylobacter fetus venerealis [7]. Bulls carry C. $f$. venerealis subclinically in their prepuce, and older bulls above three years may remain permanently infected and also serve as source of infection through the use of semen from infected bulls in artificial insemination (AI) programmes $[2,10]$. Sub-speciation of C. $f$. venerealis has been an area of some interest and there is an unusually high prevalence of $C . f$. venerealis biovar intermedius in South Africa [11]; however, the prevalence of this isolate has not been studied in Nigeria. Campylobacter $f$. fetus, found in the genital and intestinal tracts of cattle and

\section{Biomed Central}


sheep $[2,10]$, is also a cause of infectious infertility in cattle and is also reported to cause a wide variety of invasive diseases in humans [12].

A survey of $C$. fetus in a communal grazing area in South Africa showed a high prevalence of $28.7 \%$ [13], and $40-47 \%$ of dairy cows were found to be seropositive in one study in the USA [14]. Some field studies have been done in Nigeria [4,15-18], reporting animal-level prevalences of $2.9-11 \%$ and herd-level prevalences of 20-22\%; however, these were done on few herds and in limited locations, and in some cases targeted animals with a history of reproductive failure. The occurrence of BGC is believed to be grossly under-estimated and under-reported in Africa [7,10].

Trichomonosis is caused by Tritrichomonas foetus. Bulls are primary reservoirs of $T$. foetus whereas cows clear the infection spontaneously. Strong evidence exists that bulls older than 4 years rarely recover spontaneously and are long-term carriers [19]. Transmission occurs during natural mating; however, infection affects neither semen quality nor sexual behaviour [20]. Semen used in AI may also be a source of transmission, as the organism can survive the standard AI processing methods [21]. Bull infection rates range from relatively low $(0-4 \%)$ in some herds to high (27-33\%) in others [5,22,23].

Estimates of annual losses to the USA beef industry as a result of trichomonosis have been as high as US\$ 650 million [24]. Despite the potentially huge economic losses due to infertility, cost of culling and replacement, and cost of treatment [23], the prevalence and impact of this disease in Nigeria is largely unknown. The only studies conducted on T. foetus in Nigeria were by Adeyeye et al. [25], Akinboade [26] and Ayoade et al. [27] who reported prevalences of $0 \%, 14.9 \%$ and $100 \%$ respectively.

There have been no studies on the concurrence of campylobacteriosis, trichomonosis and brucellosis in Nigeria, nor any recent studies covering different states and production systems. Concurrent herd infection with trichomonosis and C. $f$. venerealis in bulls was shown to be common in South Africa [13] and northern Australia [5]. Concurrent infection with C. fetus and T. foetus has been reported to cause reproductive failure in camels [28]. However, there is no evidence to suggest that infection with one agent predisposes to infection with the other agent [5]. Determining the extent of concurrence of diseases is a useful tool in devising control strategies likely to impact on both diseases.

Continuous movement of cattle and sharing of bulls is practiced in Nigeria, putting many herds at risk of venereal infections. Over the years both governmental and non-governmental interventions in the livestock sector have imported semen for AI programmes; however, there is no information on the screening of AI semen for C. fetus, T. foetus or Brucella abortus in Nigeria. The desire of the Nigerian government to promote dairy production and the upsurge of commercial dairy production through the use of AI programmes to upgrade Nigerian indigenous cattle, without proper screening of semen for infectious reproductive diseases, are of concern to the livestock industry. Therefore, this study was designed in order to determine the animal- and herd-level prevalences of campylobacteriosis and trichomonosis in mature bulls in cattle herds in three important cattle producing states of northern Nigeria, as well as the concurrence of the two infections with each other and with $B$. abortus infection.

\section{Materials and methods}

The research protocol for this study was approved by the Animal Use and Care Committee and the Research Committee of the University of Pretoria (Protocol no. V073-08).

\section{Sampling area and sample size}

Three states (Kaduna, Kano and Adamawa) out of the 19 northern states of Nigeria were sampled (Figure 1). The selection was based on their location, proximity to a reliable laboratory, farming systems, human and animal populations, cooperation from farmers, sharing of international borders and variety of animal breeds.

In order to estimate the herd-level prevalence of campylobacteriosis and trichomonosis, a multistage sampling strategy was used. Assuming an estimated herd prevalence $\left(P_{\text {exp }}\right)$ of $20 \%$ for both diseases, an absolute allowable error $(d)$ of $7.5 \%$ and a confidence level of $95 \%$, the formula $n=1.96^{2 *} P_{\exp } *\left(1-P_{\exp }\right) / d^{2}$ [29] was used to calculate a required sample size of 110 herds using simple random sampling. A low intra-cluster correlation coefficient of $\rho=0.1$ was used to account for geographic clustering within wards and local government areas (LGAs), resulting in a design effect $(D)$ of 2.2. This was calculated using the formula $D=1+(b-1)^{*}$ roh [30], where $b$ is the average number of samples per cluster, in this case approximately 13 farms per LGA, and roh is the rate of homogeneity, equivalent to the intracluster correlation coefficient $(\rho)$ in single-stage cluster sampling. This resulted in a required sample size of 242 herds. To ensure even distribution across states, each state was divided into 3 geographic zones based on administrative divisions. In each zone, two LGAs were randomly selected, giving a total of six LGAs per state (Figure 1). On average in each LGA, 5 wards were randomly selected, and in each ward 3 herds were sampled, giving 271 herds in total, of which 250 contained bulls eligible for sampling. An infected herd was defined as one in which one or more C. fetus or T. foetus infected bulls were detected. 


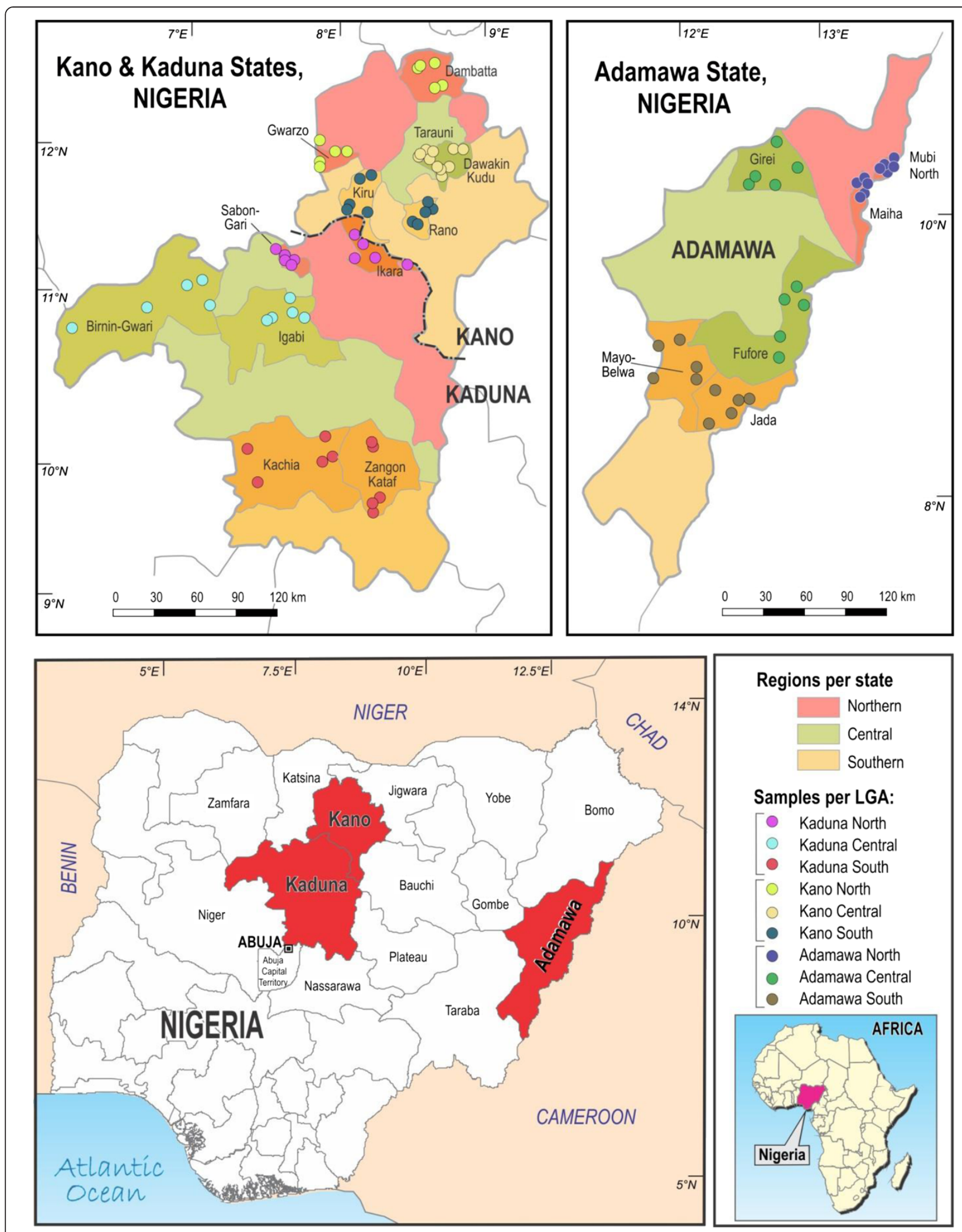

Figure 1 Map of Nigeria showing the three states, 18 local government areas and 89 wards sampled in northern Nigeria. 


\section{Sampling for Campylobacter fetus and Tritrichomonas foetus}

All post-pubertal bulls present in selected herds were sampled once for both $C$. fetus and $T$. foetus by collecting preputial samples using preputial scraping technique as follows: The prepuce was cleaned with paper towel and the hair around the preputial orifice clipped where necessary. The samples were collected by insertion of a 53-cm rigid AI pipette attached to a sterile $20 \mathrm{ml}$ disposable hypodermic syringe, through the preputial orifice to the fornix of the prepuce. The preputial lining and glans penis were scraped vigorously for about 45 seconds while applying vacuum with the plunger of the syringe as described by Irons et al. [2]. The pipette was withdrawn gradually while still applying negative pressure to the plunger. For $C$. fetus, the sample was directly inoculated in Mueller Hinton broth (Oxoid, CM0405B) for transportation to the laboratory for isolation, while for $T$. foetus, the same sample was inoculated into a combined transport and culture media as described below. In addition, a drop of the fresh sample was put on a clean glass slide, a cover slip was placed on the sample, and it was viewed directly using a normal bright field microscope.

\section{Isolation of Campylobacter fetus from bulls}

Preputial samples were streaked out using a $25 \mu$ loop onto the surface of Columbia agar base (Oxoid, CM0331B) containing Campylobacter Skirrow's supplement (Oxoid SR0069E), 7\% citrated/defibrinated blood, polymixin B, trimethoprim, vancomycin and amphotericin B and blood agar without antibiotics. Plates were incubated in a hydrogen enriched microaerophilic atmosphere consisting of $10 \% \mathrm{CO}_{2}, 10 \% \mathrm{H}_{2}$, and $80 \% \mathrm{~N}_{2}$ using Campylobacter system Gas Generating Kit (Oxoid, BR0060A) with palladium catalyst at $37^{\circ} \mathrm{C}$ for 72 hours, shielded from light. At $72 \mathrm{~h}$, a representative of a dewdrop colony which was smooth, shiny and grey to pink in colour with organisms that were Gram-negative, vibroid in shape, oxidase- and catalase-positive was transferred to blood agar base (Oxoid, CM0055), streaked for purity and incubated under the same conditions as the sample described above. Each culture and incubation run was verified by using control strains of C. f. fetus and C. f. venerealis (ATCC 33247 and 19438 respectively). The identification of each colony obtained was confirmed using the Dry spot latex agglutination test (Oxoid, DR150M), according to manufacturer's instructions.

The isolates were subjected to biochemical testing for $\mathrm{H}_{2} \mathrm{~S}$ production using TSI agar (Oxoid, CM0277B), for aerobic growth, for growth at $25^{\circ} \mathrm{C}$ and $42^{\circ} \mathrm{C}$ and in the presence of $1 \%$ glycine and $3.5 \% \mathrm{NaCl}$, and for sensitivity to cephalothin and nalidixic acid. Campylobacter fetus grew at $25^{\circ} \mathrm{C}$, did not produce $\mathrm{H}_{2} \mathrm{~S}$ using TSI agar, was sensitive to cephalothin but resistant to nalidixic acid, and was oxidase and catalase positive. Two phenotyping tests, i.e. tolerance to $1 \%$ glycine and $\mathrm{H}_{2} \mathrm{~S}$ production using lead acetate paper $[10,11]$, were used to differentiate the subspecies. Campylobacter $f$. fetus grew on $1 \%$ glycine medium and produced $\mathrm{H}_{2} \mathrm{~S} ; C$. $f$. venerealis did not grow on $1 \%$ glycine and did not produce $\mathrm{H}_{2} \mathrm{~S}$; C. $f$. venerealis biovar intermedius did not grow on $1 \%$ glycine but produced $\mathrm{H}_{2} \mathrm{~S}$ in L-cysteine supplemented "sensitive medium" [11].

\section{Isolation of Tritrichomonas foetus from bulls}

For logistical reasons, two methods of isolation were used in this study; however, they were considered equal. The first 300 preputial samples were each directly inoculated into a commercial transport and field culture kit (InPouch $^{\mathrm{Tm}}$ TF system; Biomed Diagnostics, San Jose, CA, USA) that allows for growth of the trichomonads and direct microscopic examination without aspiration of the inoculums. The last 302 samples were each placed in a sterile Whirl-Pak ${ }^{\otimes}$ bag containing $10 \mathrm{ml}$ of "Trichomonas medium" enriched with heat-inactivated foetal calf serum (CN 3332 Highveld Biological, Lyndhurst, South Africa) $(80 \mathrm{ml} / \mathrm{l}$ medium) and $2 \mathrm{ml}$ chloramphenicol/l (CAPS Pharmaceuticals, South Africa). The medium was examined directly through the plastic pouch in the field under a standard light microscope using a magnification of 100 or more for the presence of motile protozoa with three flagella. The pouch was incubated at $37^{\circ} \mathrm{C}$ and examined every $24 \mathrm{~h}$ for 7 days. In addition, the prepared enriched "Trichomonas medium" was dispensed aseptically into sterile McCartney bottles in $10 \mathrm{ml}$ aliquots and used as both transport and culture medium for all the samples collected for isolation of $T$. foetus with microscopic examination of the medium at intervals from day 1 to day 7 after inoculation, taken from the bottom of the bottle. For wet preparation or direct microscopy, a drop of inoculated sample was put on a clean glass slide with a cover slip for immediate observation under the microscope at $\times 10$ and $\times 40$ magnification. The result was recorded as positive when trichomonad organisms displaying unique morphological characteristics were present, or negative if there was no growth of trichomonads.

\section{Other data collected}

Herds were categorized into the four main management systems as follows: Pastoral herds are those in which the cattle graze communally during the rainy season, but may cover large distances in search of pasture and water during the critical period of the dry season. Natural pasture is the major source of feed for livestock in the pastoral system. Agro-pastoral herds are herds that go out for communal grazing in the morning and return in the 
evening without covering large distances but in addition supplementary feeds are provided. The farmers are involved in agricultural activities and use crop residues for their livestock. Commercial farms are usually organized and fenced farms with paddocked, improved pasture and a regular supply of supplementary feeds. Zero-grazing cattle are tethered and feed is constantly supplied to them.

The breed of each animal was recorded in the following categories: Bunaji, Gudali (Adamawa Gudali and Sokoto Gudali), other Bos indicus (Rahaji, Wadara, Ndama and Brahman), Bos taurus (Friesian, Simmental, Jersey and Brown Swiss) and B. indicus $\times$ B. taurus crosses. Age was estimated using farm records, dentition and, in some cases, cornual rings.

As part of a separate study [31], all the bulls sampled in this study were also tested for brucellosis using the Rose-Bengal plate-agglutination test, with confirmation using a competitive enzyme-linked immunosorbent assay kit (COMPELISA, VLA, Weybridge, UK).

\section{Data analysis}

All statistical analyses were done using Stata 12 (Stata Corporation, College Station, TX, USA). The prevalences of campylobacteriosis and trichomonosis, overall and within states, age, breed and management systems were estimated both at animal and herdlevels, taking into account sampling weights in the multistage survey design. For each ward the sampling fraction was calculated as the product of the proportion of wards sampled within each LGA and the proportion of LGAs sampled within each state. The sampling weight was then calculated as the inverse of the sampling fraction. Since it was not possible to calculate the proportion of farms sampled within each ward, but all eligible animals on each farm were sampled, the same sampling weight was assigned to every animal within a ward. Sampling weights were then used to weight the contribution of each bull's test result to the overall prevalence and to adjust the standard error to account for clustering, using the 'svy' commands of Stata 12.
Prevalence estimates were then compared using the Chi-square test, corrected for the survey design using the second-order correction of Rao and Scott [32]. At the animal level, true prevalence (TP) was then calculated by correcting the apparent prevalence point estimates and confidence limits using the formula described by Rogan and Gladen [33]: $\mathrm{TP}=(\mathrm{AP}+\mathrm{Sp}-1) /(\mathrm{Se}+\mathrm{Sp}-1)$, where $\mathrm{AP}=$ apparent prevalence, $\mathrm{Se}=$ sensitivity, $\mathrm{Sp}=$ specificity. The values used for sensitivity and specificity of the culture system for detection of C. fetus were 94.0\% [34] and $100 \%$ [35] respectively, and for $T$. foetus detection they were $76.0 \%$ and $98.5 \%$ respectively [36].

The association of animal-level C. fetus infection with age, breed and management system was then analysed using a multivariable logistic regression model with state as a fixed effect and LGA, ward and herd as nested random effects. The concurrent presence of brucellosis was assessed at both the animal and herd level using the chisquare test and the strength of association estimated using the odds ratio.

\section{Results}

Herd-level prevalence of campylobacteriosis

A total of 250 herds containing 602 bulls, with between 1 and 24 bulls per herd (median: 1 ; interquartile range: $1,2)$ were sampled, with 78 herds containing at least one bull positive for $C$. fetus, giving a herd-level prevalence, adjusted for sampling weights, of $25.5 \%$ (95\% CI: 19.432.7). Herd-level prevalence was highest in Adamawa state $(P<0.001)$ (Table 1$)$, and varied between management systems $(P=0.03)$, being higher in pastoral $(43.5 \%, 95 \%$ CI: 24.7-64.4) than in agro-pastoral (17.4\%, 95\% CI: $10.8-$ 26.8) systems $(P=0.01)$.

\section{Animal-level prevalence of campylobacteriosis}

Of the 602 bulls tested, 108 were positive for C. fetus; the animal-level prevalence, adjusted for the survey design and test sensitivity and specificity, was 16.4\% (95\% CI: 13.0-20.7) (Table 2). There was a significant increase in prevalence of $C$. fetus infection with increasing age, with bulls $>7$ years having the highest prevalence (Table 3), also seen in the multivariable model (Table 4).

Table 1 Prevalence of herds with Campylobacter fetus-positive bulls in three states of northern Nigeria, adjusted for sampling weights

\begin{tabular}{|c|c|c|c|c|c|c|c|}
\hline State & Herds sampled & Negative & Cff & Cfv & Herds with Cff \& Cfv & Total positive & $95 \% \mathrm{Cl}$ \\
\hline Adamawa & 94 & 44 & 10 & 45 & 5 & $50(51.3 \%)^{a}$ & $37.0,65.4$ \\
\hline Kaduna & 93 & 74 & 6 & 14 & 1 & $19(20.7 \%)^{b}$ & $14.5,28.7$ \\
\hline Kano & 63 & 54 & 2 & 8 & 1 & $9(14.3 \%)^{b}$ & $6.8,29.2$ \\
\hline Total & 250 & $172(74.5 \%)$ & $18(6.3 \%)$ & $67(21.7 \%)$ & $7(2.5 \%)$ & $78(25.5 \%)$ & $19.4,32.7$ \\
\hline
\end{tabular}

$\overline{a, b}$ Values with different superscripts are significantly different $(P<0.01)$.

Key:

Cff Campylobacter fetus fetus.

Cfv Campylobacter fetus venerealis. 
Table 2 Prevalence of Campylobacter spp. in individual bulls from three states in northern Nigeria, adjusted for sampling weights and for test sensitivity and specificity

\begin{tabular}{|c|c|c|c|c|c|}
\hline \multicolumn{2}{|l|}{ State } & \multicolumn{2}{|c|}{ No. of positive bulls } & \multirow{2}{*}{$\begin{array}{l}\text { Total positive for } \\
\text { Campylobacter spp. }\end{array}$} & \multirow[t]{2}{*}{$95 \% \mathrm{Cl}$} \\
\hline & No. sampled & C. fetus fetus & C. fetus venerealis & & \\
\hline Adamawa & 235 & 12 & 63 & $75(31.8 \%)^{\mathrm{a}}$ & $23.3,41.9$ \\
\hline Kaduna & 257 & 6 & 15 & $21(8.3 \%)^{b}$ & $5.9,12.4$ \\
\hline Kano & 110 & 2 & 10 & $12(11.6 \%)^{b}$ & $7.6,17.2$ \\
\hline Overall & 602 & $20(3.2 \%)$ & $88(13.3 \%)$ & $108(16.4 \%)$ & $13.0,20.7$ \\
\hline
\end{tabular}

${ }^{\mathrm{a}, \mathrm{b}}$ Values with different superscripts are significantly different $(P<0.01)$.

Infection was apparently most prevalent in the Gudali breed (Table 3). However, after adjustment for state, management system and age, the odds of infection tended to be highest in Bos taurus breeds (Table 4). Crude animal-level prevalence of $C$. fetus did not differ significantly between the management systems (Table 3 ). However, after adjustment for state, age and breed, the odds of a bull being positive were significantly higher for pastoral systems than for zero-grazing $(P=0.001)$ and agro-pastoral $(P<0.001)$ systems (Table 4$)$.

\section{Distribution of $C$. $f$. fetus, $C$. $f$. venerealis and}

\section{C. $f$. venerealis biovar intermedius strains}

In all states, $C$. $f$. venerealis was isolated more frequently than $C$. f. fetus. The distribution of $C$. f. fetus, C. f. venerealis and both subspecies in herds and individual bulls in the various states are shown in Tables 1 and 2 respectively. Of

Table 3 Animal-level prevalence of Campylobacter fetus in bulls in three northern states of Nigeria by management system, age and breed, adjusted for sampling weights and test sensitivity and specificity

\begin{tabular}{|c|c|c|c|}
\hline Variable & $\mathrm{n}$ & $\%$ positive & $95 \% \mathrm{Cl}$ \\
\hline \multicolumn{4}{|l|}{ Management system } \\
\hline Zero-grazing & 68 & 17.6 & $12.6,23.9$ \\
\hline Commercial & 31 & 24.7 & $9.9,50.1$ \\
\hline Agro-pastoral & 347 & 13.5 & $8.4,21.0$ \\
\hline Pastoral & 156 & 22.2 & $14.8,32.0$ \\
\hline \multicolumn{4}{|l|}{ Age } \\
\hline$<4$ years & 23 & 8.8 & $1.6,36.2$ \\
\hline 4-5 years & 339 & $13.6^{\mathrm{a}}$ & $10.4,17.7$ \\
\hline 5-7 years & 200 & 18.7 & $12.1,27.9$ \\
\hline$>7$ years & 30 & $33.4^{b}$ & $16.6,56.3$ \\
\hline \multicolumn{4}{|l|}{ Breed } \\
\hline Bunaji & 344 & $11.5^{c}$ & $8.1,16.1$ \\
\hline Gudali & 149 & $28.8^{d}$ & $19.8,39.9$ \\
\hline Bos taurus & 28 & 17.8 & $5.2,46.7$ \\
\hline B. taurus $\times B$. indicus & 31 & 18.1 & $3.5,58.6$ \\
\hline Other B. indicus & 50 & 16.4 & $7.3,32.9$ \\
\hline
\end{tabular}

the positive herds, $76.9 \%$ had C. $f$. venerealis alone, $14.1 \%$ had C. f. fetus alone and 9.0\% had both C. f. venerealis and C. f. fetus. Of the 88 C. $f$. venerealis isolates, 81 (92\%) were C. $f$. venerealis biovar intermedius strains. Both $C$. $f$. fetus and $C$. $f$. venerealis were never found together in the same bull. Both $C$. $f$. fetus and $C$. $f$. venerealis were found more in herds with bulls $>7$ years $(7.5 \%$ and $27.5 \%)$ than bulls $<4$ years $(0 \%$ and $8.3 \%)$ respectively. The prevalence of $C$. $f$. fetus and $C$. $f$. venerealis were higher in zero-grazing herds (25.0\% and 62.5\%), followed by pastoral herds (10.5\% and 38.2\%), commercial herds $(13.0 \%$ and $17.4 \%)$ and agro-pastoral herds $(3.5 \%$ and $20.3 \%)$ respectively.

Table 4 Associations of state, management system, age and breed with Campylobacter fetus infection in bulls in three northern states of Nigeria: results of a multivariable logistic regression model

\begin{tabular}{lccc}
\hline Variable & Odds ratio & $\mathbf{9 5 \% ~ C l}$ & $\boldsymbol{P}$ \\
\hline State & & & \\
$\quad$ Kaduna & $1^{*}$ & - & - \\
Adamawa & 10.1 & $4.0,25.5$ & $<0.01$ \\
$\quad$ Kano & 1.3 & $0.5,3.5$ & 0.61 \\
Management system & & & \\
$\quad$ Zero-grazing & $1^{*}$ & - & - \\
Commercial & 1.9 & $0.3,10.8$ & 0.47 \\
Agro-pastoral & 1.5 & $0.5,4.6$ & 0.44 \\
Pastoral & 7.3 & $2.2,24.3$ & $<0.01$ \\
Age & & & \\
<4 years & 0.9 & $0.2,4.6$ & 0.91 \\
4-5 years & $1^{*}$ & - & - \\
5-7 years & 1.3 & $0.7,2.2$ & 0.42 \\
$>$ 7 years & 3.4 & $1.3,8.7$ & 0.01 \\
Breed & & & \\
Bunaji & 1.1 & - & - \\
Gudali & 1.4 & $0.7,3.1$ & 0.34 \\
Bos taurus & 4.2 & $0.9,18.9$ & 0.06 \\
B. taurus $\times$ B. indicus & 1.6 & $0.4,6.6$ & 0.51 \\
Other B. indicus & 1.1 & $0.4,3.3$ & 0.81 \\
\hline
\end{tabular}

"Reference level. 


\section{Association between campylobacteriosis and brucellosis} There was a significant positive association between the occurrence of campylobacteriosis and brucellosis both at animal-level and at herd-level (Table 5).

\section{Prevalence of trichomonosis}

Trichomonosis was not isolated from any of the bulls in this study. The upper 95\% confidence limit for the prevalence of positive test results in the population was $0.50 \%$. The absence of any positive tests suggested that the specificity of the test was greater than the $98.5 \%$ reported by Cobo et al. [36]; therefore, adjusting for a test sensitivity of $76 \%$ and specificity of $100 \%$, an upper $95 \%$ confidence limit of $0.65 \%$ was calculated for the true animal-level prevalence of trichomonosis in the population.

\section{Discussion}

In the recent past, most emphasis has been placed on brucellosis as the most prominent reproductive disease of cattle in Nigeria. However, it is evident from the result of this study that C. fetus is common in northern Nigeria and may be an important cause of infertility. A similar study performed in Nigeria 20 years ago reported a lower prevalence of $2.9 \%$ of cattle and $20 \%$ of herds [4]. Although the authors sampled both bulls and cows, the herd-level prevalence was comparable to our study; however, the animal-level prevalence was lower, suggesting that there has been an increase in the prevalence of this disease.

An animal-level C. fetus prevalence of $10-15 \%$ with a herd-level prevalence of $53.8 \%$ was reported in Malawi [37] and animal-level prevalences of between 29\% and $47 \%$ have been reported in other countries $[13,14]$. The proximity of Adamawa state to the Cameroon border may contribute to the high prevalence in the state;

Table 5 Concurrent occurrence of campylobacteriosis and brucellosis at animal and herd-level in cattle herds from three states in northern Nigeria

\begin{tabular}{|c|c|c|c|c|}
\hline & & \multicolumn{2}{|c|}{ Campylobacteriosis } & \multirow[b]{2}{*}{ Total } \\
\hline & & + & - & \\
\hline \multicolumn{5}{|c|}{ Animal-level (bulls) } \\
\hline & Brucellosis + & 81 & 131 & 212 \\
\hline & Brucellosis - & 27 & 363 & 390 \\
\hline & Total & 108 & 494 & 602 \\
\hline \multicolumn{5}{|c|}{ Odds ratio $=8.3(95 \% \mathrm{Cl}: 5.2,13.4), x^{2}=91.3, P<0.0001$} \\
\hline \multicolumn{5}{|l|}{ Herd-level } \\
\hline & Brucellosis + & 76 & 121 & 197 \\
\hline & Brucellosis - & 2 & 51 & 53 \\
\hline & Total & 78 & 172 & 250 \\
\hline \multicolumn{5}{|c|}{ Odds ratio $=16.0(95 \% \mathrm{Cl}: 3.8,67.7), x^{2}=23.6, P<0.0001$} \\
\hline
\end{tabular}

Mshelia et al. [7,17] reported a high incidence of BGC in Nigeria, where natural breeding of cattle is widely practiced, and implicated mass cattle movement across the borders of Nigeria as a major risk factor.

The crude association between breed and C. fetus prevalence, with the highest prevalence in Gudali bulls, disappeared after adjustment for state, management system and age. This was likely due to confounding by state, since Gudali bulls were encountered predominantly in Adamawa state which has a higher prevalence. In fact, after adjustment for state, the odds of being C. fetus positive tended to be higher for Bos taurus bulls than for Gudali bulls. It is possible that Bos taurus may be more susceptible than indigenous breeds to campylobacteriosis. Klastrup and Halliwell [37] also found more of the disease in exotic than indigenous cattle. However, further studies including adjustment for other possible confounders are required to be able to determine breed susceptibility.

The strong association between $C$. fetus infection and the pastoral management system, revealed in the multivariable analysis, was initially confounded by state, since more of the pastoral herds were found in the lower prevalence Kaduna state than in Adamawa state. Comingling, sharing of grazing land and common watering points, which are common in northern Nigeria, contribute to the spread of BGC. A prevalence of $28.7 \%$ was reported in communal grazing areas in South Africa [13]. Trespassing bulls from neighboring herds may double the risk of a herd being positive to BGC [38], and transmission in cattle is known to be associated with sharing, renting or mixing of bulls and other cattle on common grazing land or extensive cattle management $[5,8,38]$.

The prevalence of BGC was higher in older bulls. This is in agreement with other reports [2,39]. The retention of infection in older bulls than the younger bulls may be due to the increase in number and size of the irregular crypts in the epithelium of the penis and persistent colonization of the lower reproductive tract of mature bulls by C. fetus [39]. However, McCool et al. [5] and Swai et al. [40] observed that both younger and older bulls could remain carriers after infection; this requires further investigation.

Of the two subspecies of C. fetus, C. f. venerealis was more common, which is in agreement with other studies $[2,4,8]$. It is noteworthy that $C$. $f$. venerealis is more pathogenic than $C$. f. fetus $[10,41]$. This is the first report of C. fetus subsp. venerealis biovar intermedius in Nigeria. This has also been reported from South Africa [11]. The latter study also demonstrated the incorrect classification based on subspecies-specific PCR assays, making phenotypic characterization following bacterial culture superior to PCR assays for identification of C. fetus subspecies. In a genomic analysis of $C$. fetus subspecies, 
two assays were specific for $C$. fetus subsp. venerealis AZUL-94 strain, with a further single assay specific for the AZUL-94 strain and C. fetus subsp. venerealis biovar intermedius in Australia [42]. The assays developed in the genomic analysis of $C$. fetus subspecies highlight the complexity of targeting strain specific virulence genes for field studies for the molecular identification and epidemiology of C. fetus [42].

The strong association between the occurrences of campylobacteriosis and brucellosis suggests that, although their major mode of transmission is different, they share some common risk factors. The separate study on brucellosis using the same bulls [31] showed that the infection was more prevalent in older bulls and in the pastoral management system, and half of all the bulls that had hygroma, a common manifestation of brucellosis, also had BGC. This is consistent with the findings of Zhao et al. [41], who reported some degree of mixed infections of campylobacteriosis and bovine brucellosis. Further investigation of risk factors for the two diseases would be useful in order to inform control measures for both diseases. Another possible explanation may be that one infection predisposes an animal to the other infection, possibly due to an effect on the immune system. Neta et al. [43] reported that B. abortus invades phagocytic and non-phagocytic host cells of cattle, inhibiting phagosome-lysosome fusion thereby affecting the innate and adaptive immunity against brucellosis. Such cattle may also be susceptible to campylobacteriosis.

Tritrichomonas foetus was not isolated from any of the bulls sampled in this study despite using an efficient diagnostic protocol, including a gold standard test [21], and a commercial transport and field culture kit, with a sensitivity of up to $100 \%$ [44] on half of the samples. Even assuming a test sensitivity of only $76 \%$, we could be $95 \%$ certain that the true prevalence of trichomonosis in the area was below $0.65 \%$. Considering the extent of bull sharing and comingling of cattle in our study area, it would be expected that, were the infection present, the true prevalence would be far greater than $0.65 \%$, therefore it is probable that the disease is absent in our study area. This finding is in agreement with surveys conducted in 384 bulls in Malawi [37]; in 58 bulls in Tanzania [40] and most recently in 299 males, $101 \mathrm{fe}-$ male cattle and 3 abomasal and foetal fluids in northern Nigeria [25]. It therefore suggests that trichomonosis may not be a significant problem in northern Nigeria despite reports of its occurrence in southern Nigeria $[26,27]$. Breed and ecological differences may be responsible for the variation in disease occurrence in northern and southern Nigeria. Most of the breeds in the south are the short and humpless Ndama, Muturu and Keteku; while the climate is relatively hot with high humidity as opposed to the relatively cool and dry northern parts.
Very recently it was shown that $T$. foetus may transform into pseudocysts or endoflagellar form because of adverse environmental conditions or presence of drugs [45] and may therefore not be detected.

\section{Conclusion}

Bovine genital campylobacteriosis should be considered in all investigations of herd infertility problems in northern Nigeria, since more than $50 \%$ of herds are infected in some areas. The risk of $C$. fetus infection is highest in the pastoral management system usually practiced by the Fulanis in northern Nigeria. Consideration should therefore be given to recommending alternative management systems, such as the agro-pastoral system, which carries a lower risk, and specific preventative measures such as vaccination. Campylobacteriosis and brucellosis often occur together in herds, and may share similar risk factors; therefore control measures can be instituted to target both diseases.

\section{Competing interest}

The authors declare that they have no competing interests.

\section{Authors' contributions}

HMM initiated and designed the study, was responsible for herd visits, collection, planning of data, analysis and interpretation of data and writing the draft manuscript. PNT was involved in the design of the project, performed the statistical analysis and interpretation, and critical revision of the paper. $\mathrm{PCl}$ also took part in the planning of the study and proof reading the article. JK was involved in the initial data input, analysis, interpretation and revision of the manuscript. All authors have read and approved the final manuscript.

\section{Acknowledgements}

The authors greatly acknowledged Prof. JO Bale, Dr. A Ibrahim and Dr. MA Qadeers for their professional and technical assistance. Excellent cooperation was received from farm owners, their Fulani herdsmen and managers. We express our thanks to staff of AI Unit, NAPRI, A.B.U., Zaria; Department of Veterinary Public Health and Preventive Medicine, A.B.U., Zaria; National Veterinary Research Institute, Yola Zonal Office; Ministry of Agriculture, Kano; and Geoinformation and Mapping Unit, University of Pretoria. The study was partially funded by the Department of Production Animal Studies, Faculty of Veterinary Science, University of Pretoria, for which we are grateful.

\section{Author details}

${ }^{1}$ Department of Production Animal Studies, Faculty of Veterinary Science, University of Pretoria, Private Bag X04, Onderstepoort 0110, South Africa. ${ }^{2}$ Animal Production Programme, School of Agriculture and Agricultural Technology, Abubakar Tafawa Balewa University, P. M. B. 0248, Bauchi 740001, Nigeria. ${ }^{3}$ Department of Veterinary Public Health and Preventive Medicine, Ahmadu Bello University, Zaria, Nigeria.

Received: 5 September 2012 Accepted: 1 August 2013 Published: 9 August 2013

\section{References}

1. Devenish J, Brooks B, Perry K, Milnes D, Burke T, McCabe D, Duff S, LutzeWallace $\mathrm{CL}$ : Validation of a monoclonal antibody-based capture enzymelinked immunosorbent assay for detection of Campylobacter fetus. Clin Diagn Lab Immunol 2005, 12:1261-1268.

2. Irons PC, Schutte AP, Van Der Walt ML, Bishop GC: Genital campylobacteriosis in cattle. In Infectious Diseases of Livestock. 2nd edition. Edited by Coetzer JAW, Tustin RC. Cape Town: Oxford University Press; 2004:1459-1468. 
3. Kimsey PB: Bovine trichomonosis. In Current Therapy in Large Animal Theriogenology. Edited by Youngquist RS. Philadelphia: WB Saunders Company; 1997:275-279.

4. Bawa EK, Adekeye JO, Oyedipe EO, Umoh JU: Prevalence of bovine campylobacteriosis in indigenous cattle of three states in Nigeria. Trop Anim Health Prod 1991, 23:157-160.

5. McCool CJ, Townsend MP, Wolfe SG, Simpson MA, Olm TC, Jayawardhana GA, Carney JV: Prevalence of bovine venereal disease in the Victoria River district of the northern territory: Likely economic effects and practical control measures. Aust Vet J 1988, 65:153-156.

6. BonDurant $\mathrm{RH}$ : Venereal diseases of cattle: Natural history, diagnosis and the role of vaccines in their control. Vet Clin N Am Food A 2005, 21:383-408.

7. Mshelia GD, Amin JD, Woldehiwet Z, Murray RD, Egwu GO: Epidemiology of bovine venereal campylobacteriosis: Geographic distribution and recent advances in molecular diagnostic techniques. Repro Domest Anim 2010, 45:221-230.

8. Hum S: Bovine abortion due to Campylobacter fetus. Aust Vet J 1987, 64:319-320

9. Rae DO: Impact of trichomoniasis on the cow-calf producer's profitability. J Am Vet Med Ass 1989, 194:771-775.

10. OIE (Office International des Epizooties): Bovine genital campylobacteriosis. In Manual of Diagnostic Tests and Vaccines for Terrestrial Animals. World Organization for Animal Health, Paris, France. 2011:661-670. http://www.oie. int/fileadmin/Home/eng/Health_standards/tahm/2.04.05_BGC.pdf. 2011:661670.13.2.2012.

11. Schmidt T, Venter EH, Picard JA: Evaluation of PCR assays for the detection of Campylobacter fetus in bovine preputial scrapings and the identification of subspecies in South African field isolates. J $S$ Afr Vet Assoc 2010, 81:87-92.

12. Fujihara $N$, Takakura S, Saito $T$, linuma $Y$, Ichiyama S: A case of perinatal sepsis by Campylobacter fetus subsp. fetus infection successfully treated with carbapenem- case report and literature review. J Infection 2006, 53:199-202.

13. Pefanis SM, Herr S, Venter CG, Kruger LP, Queiroga CC, Amaral L: Trichomoniasis and campylobacteriosis in bulls in the Republic of Transkei. J S Afr Vet Assoc 1988, 59:139-140.

14. Akhtar A, Riemann HP, Thurmond MC, Franti CE: The association between antibody titres against Campylobacter fetus and reproductive efficiency in dairy cattle. Vet Res Commun 1993, 17:95-107.

15. Nuru S: Infections bovine abortion in northern Nigeria, PhD thesis. Zaria, Nigeria: Faculty of Veterinary Medicine. Ahmadu Bello University; 1974.

16. Bawa EK, Voh AA Jr, Oyedipe EO, Adekeye JO, Dawuda PM, Rekwot PI: Campylobacteriosis and bovine infertility and abortion in an artificial insemination programme in Nigeria. Vet Rec 1987, 20:483.

17. Mshelia GD, Amin JD, Egwu GO, Yavari CA, Murray RD, Woldehiwet Z: Detection of antibodies specific to Campylobacter fetus subsp. venerealis in the vaginal mucous of Nigerian breeding cows. Vet Ital 2010, 46:337-344.

18. Mshelia GD, Amin JD, Egwu GO, Woldehiwet Z, Murray RD: The prevalence of bovine venereal campylobacteriosis in cattle herds in the Lake Chad basin of Nigeria. Trop Anim Health Prod 2012, 44:1487-1489.

19. BonDurant $\mathrm{RH}$ : Pathogenesis, diagnosis and management of trichomoniasis in cattle. Vet Clin N Am Food A 1997, 13:345-361.

20. Martín-Gómez S, González-Paniello R, Pereira-Bueno J, Ortega-Mora LM: Prevalence of Tritrichomonas foetus infection in beef bulls in northwestern Spain. Vet Parasitol 1998, 28:265-268.

21. Rae DO, Crews JE: Tritrichomonas foetus. Vet Clin N Am Food A 2006, 22:595-611

22. Madoroba E, Gelaw A, Hlokwe T, Mnisi M: Prevalence of Campylobacter fetus and Tritrichomonas foetus among cattle from Southern Africa. Afr J Biotechnol 2011, 10:10311-10314.

23. Rae DO, Crews JE, Greiner EC, Donovan GA: Epidemiology of Tritrichomonas foetus in beef bull populations in Florida. Theriogenology 2004, 61:605-618.

24. Speer CA, White MW: Bovine trichomoniasis. Large Anim Vet 1991, 46:18-20.

25. Adeyeye AA, Ate IU, Bale JO, Lawal Al: A survey for bovine trichomoniasis in cattle at slaughter in the Sokoto metropolitan abattoir, Sokoto state, Nigeria. Sokoto J Vet Sci 2011, 8:18-21.

26. Akinboade OA: Incidence of bovine trichomoniasis in Nigeria. Rev Elev Med Vet Pays trop 1980, 33:381-384.
27. Ayoade GO, Agbede SA, Ogungbade SG: Occurrence of Tritrichomonas foetus (Riedmuller, 1928) in settled cattle herd in Ibadan, Nigeria. Trop Anim Prod Invest 1991, 1:123-125.

28. Wernery $U$, Wernery $R$ : Uterine infections in the dromedary camels-a review. In Proceedings of First Int Camel Conference: 2-6 February, 1992. Edited by Allen WR, Higgins AJ, Mayhew IG, Snow DH. Dubai, UAE; 1992:155-158.

29. Thrusfield M: Veterinary Epidemiology. 3rd edition. UK: Blackwell Science Limited, Oxford; 2005.

30. Bennett S, Woods T, Liyanage WM, Smith DL: A simplified general method for cluster-sample surveys of health in developing countries. World Health Stat Quart 1991, 44:98-106.

31. Mai HM, Irons PC, Kabir J, Thompson PN: A large seroprevalence survey of brucellosis in cattle herds under diverse production systems in northern Nigeria. BMC Vet Res 2012, 8:144. http://www. biomedcentral.com/1746-6148/8/144.

32. Rao JNK, Scott AJ: On chi-squared tests for multiway contingency tables with cell proportions estimated from survey data. Ann Stat 1984, 12:46-60.

33. Rogan WJ, Gladen B: Estimating prevalence from the results of a screening test. Am J Epidemiol 1978, 107:71-76.

34. Hum S, Brunner J, McInnes A, Mendoza G, Stephens J: Evaluation of cultural methods and selective media for the isolation of Campylobacter fetus subsp. venerealis from cattle. Aust Vet J 1994, 71:184-186.

35. Andrews PJ, Frank FW: Comparison of four diagnostic tests for detection of bovine genital vibriosis. J Am Vet Med Ass 1974, 165:65-69.

36. Cobo ER, Favetto PH, Lane VM, Friend A, VanHooser K, Mitchell J, BonDurant $\mathrm{RH}$ : Sensitivity and specificity of culture and PCR of smegma samples of bulls experimentally infected with Tritrichomonas foetus. Theriogenology 2007, 68:853-860.

37. Klastrup NO, Halliwell RW: Infectious causes of infertility/abortion of cattle in Malawi. Nord Vet Med 1977, 29:325-330.

38. Jimenez DF, Perez AM, Carpenter TE, Martinez A: Factors associated with infection by Campylobacter fetus in beef herds in the Province of Buenos Aires, Argentina. Prev Vet Med 2011, 101:157-162.

39. Cobo ER, Corbeil LB, BonDurant RH: Immunity to infections in the lower genital tract of bulls. J Repro Immunol 2011, 89:55-61.

40. Swai ES, Hulsebosch J, Vander Heijden W: Prevalence of genital campylobacteriosis and trichomonosis in crossbred breeding bulls kept on zero-grazed smallholder dairy farms in the Tanga region of Tanzania. I S Afr Vet Assoc 2005, 76:224-227.

41. Zhao H, Liu H, Du Y, Liu S, Ni H, Wang Y, Si C, Wang W, Yang J, Ling J: Development and evaluation of an indirect enzyme-linked immunosorbent assay for the detection of antibodies against Campylobacter fetus in cattle. Res Vet Sci 2010, 88:446-451.

42. Moolhuijzen PM, Lew-Tabor AE, Wlodek BM, Agüero FG, Comerci DJ, Ugalde RA, Sanchez DO, Appels R, Bellgard M: Genomic analysis of Campylobacter fetus subspecies: identification of candidate virulence determinants and diagnostic assay targets. BMC Microbio/ 2009, 9:86-97.

43. Neta AVC, Mol JPS, Xavier MN, Paixão TA, Lage AP, Santos RL: Pathogenesis of bovine brucellosis. Vet J 2010, 184:146-155.

44. Thomas MW, Harmon WM, White C: An improved method for the detection of Tritrichomonas foetus infection by culture in bulls. Agri Practice 1991, 11:13-17.

45. Pereira-Neves A, Nascimento LF, Benchimol M: Cytotoxic effects exerted by Tritrichomonas foetus pseudocysts. Protist 2012, 163:529-543.

doi:10.1186/1751-0147-55-56

Cite this article as: Mai et al.: Prevalence of bovine genital campylobacteriosis and trichomonosis of bulls in northern Nigeria. Acta Veterinaria Scandinavica 2013 55:56. 